\title{
Can Baseline Electromyography Predict Response to Biofeedback for Anorectal Disorder? A Long-Term Follow-Up Study
}

\author{
Ankita Gupta $^{\mathrm{a}, \mathrm{e}}$, Deslyn T.G. Hobson ${ }^{\mathrm{a}}$, Michelle Petro ${ }^{\mathrm{b}}$, Amar Al-Juburic, \\ Sean Francis ${ }^{\mathrm{a}}$, Thomas L. Abell ${ }^{\mathrm{d}}$
}

\begin{abstract}
Background: Biofeedback has been recommended for the treatment of anorectal disorders, especially constipation and fecal incontinence (FI). The objective of this study was to assess the long-term efficacy of biofeedback and evaluate baseline electromyography (EMG) as a predictor for maintenance of long-term improvement.
\end{abstract}

Methods: A retrospective chart review was performed on randomly selected patients who underwent biofeedback between the years 1990 and 2000. Clinical characteristics, including EMG values at baseline (resting and contraction) as well as EMG after exercises, were collected. Patients were contacted and were classified as "improved" if they had self-reported symptomatic improvement and "not-improved" if their symptoms were unchanged or worsened.

Results: A total of 41 subjects were included. Majority (85.4\%) were female, the mean age was $48.95 \pm 15.46$ (range $22-77$ years) and the median follow-up was 4 years (range 4 - 5 years). Constipation was the primary indication for biofeedback in $27 / 41$ (65.9\%), FI in $9 / 41$ $(22 \%)$ and "other" in 5/41 (12.1\%). Within constipation, $55.6 \%$ reported long-term improvement as compared to $66.7 \%$ of FI and $80 \%$ of the other patients. There was borderline difference in the baseline EMG $(3.11 \pm 1.85 \mu \mathrm{V}$, improved, and $7.41 \pm 11.01 \mu \mathrm{V}$, not improved, $\mathrm{P}=0.06)$ but no significant difference in post-exercise resting $(3.13 \pm$ $3.21 \mu \mathrm{V}$, improved, and $4.28 \pm 3.63 \mu \mathrm{V}$, not improved, $\mathrm{P}=0.33$ ) and contraction EMG between the two groups.

Conclusions: Biofeedback is an important treatment tool in anorectal

Manuscript submitted August 14, 2019, accepted August 22, 2019

aDivision of Female Pelvic Medicine and Reconstructive Surgery, Department of Obstetrics \& Gynecology, University of Louisville School of Medicine, Louisville, KY, USA

${ }^{\mathrm{b}}$ GI Associates, Jackson, MS, USA

'Division of Gastroenterology and Hepatology, Davis School of Medicine, University of California, Sacremento, CA, USA

${ }^{\mathrm{d} D i v i s i o n}$ of Gastroenterology, Hepatology and Nutrition, University of Louisville School of Medicine, Louisville, KY, USA

${ }^{e}$ Corresponding Author: Ankita Gupta, Department of Obstetrics \& Gynecology, University of Louisville School of Medicine, Louisville, KY 40202, USA. Email: ankita.gupta@louisville.edu

doi: https://doi.org/10.14740/gr1213 disorders. Over $50 \%$ of our subjects maintained their improvement 4 - 5 years after completing biofeedback therapy. A lower resting baseline EMG showed a trend of association with improvement in the long term.

Keywords: Anal electromyography; Pelvic floor muscle training; Biofeedback; Pelvic floor disorders; Fecal incontinence

\section{Introduction}

Constipation and fecal incontinence (FI) are important anorectal disorders which can significantly impact quality of life [1, 2].The use of biofeedback or "instrumental learning" has been well described in the treatment of these disorders $[1,3]$. Consensus guidelines have recommended the use of biofeedback in the short- and long-term treatment of constipation and FI with 50-75\% efficacy in the long term [1, 3-8].

With the high prevalence of anorectal disorders, attempts have been made to predict response to biofeedback. Prior studies have shown that age, depression scores, stool consistency and higher straining rectal pressure can affect response to biofeedback [9-11]. External anal sphincter electromyography $(E M G)$ has been found to determine the presence of sphincter denervation and its use as a predictor has been evaluated in the short term $[12,13]$. However, the use of EMG as a predictor for long-term efficacy of biofeedback has not been evaluated.

Our aim was to evaluate the long-term efficacy of biofeedback for anorectal disorders at a tertiary medical center that specialized in evaluation and treatment of anorectal disorders with the secondary aim to assess the role of surface EMG in predicting improved long-term outcomes. We hypothesize that patients with lower resting anal EMG values will demonstrate long-term improvement after biofeedback.

\section{Materials and Methods}

\section{Biofeedback delivery}

Historically, biofeedback at our institutions began with an explanation of the anatomy and function of pelvic floor muscles. 
Internal assessment of the pelvic floor muscles was done to correct exercise technique and assess muscles. An individualized home exercise program was prescribed. Participants were encouraged to progress exercises, with an aim of 10 times, 10 -s maximum holds and up to 50 fast contractions three times per day. Furthermore, participants were taught how to contract the pelvic floor muscles against increases in intra-abdominal pressure and were encouraged to use this technique daily.

Biofeedback was performed using the SRS Orion PC/12M Multi-Modality Biofeedback System (Acmi Circon/SRS Medical, Feeding Hills, MA, USA) with an anal sensor protected by a rigid plastic anal cone, encased in a disposable condom, and inserted with aid of lubricant. The anal sensor was connected to a computer allowing for transmission of pressure readings in centimeters of water. Patients were taught the technique for contraction of the anal sphincters while watching real-time display on the monitor screen and a full set of exercises were performed during each treatment session. This system monitored the activity of the pelvic floor and accessory muscles, making it easier for patients to learn to isolate muscles and develop better control. Resting and contraction EMG values were measured at baseline and after at least two sessions of biofeedback in microvolts $(\mu \mathrm{V})$.

\section{Patient selection}

In this study, we contacted subjects with a primary diagnosis of either chronic constipation or FI refractory to conservative management who underwent anal EMG with biofeedback between the years of 1990 and 2000. Participants were selected by random chart numbers. Subjects with anatomic defects based on imaging and physical exam were excluded. Eligible subjects had attended, at minimum, two one-on-one appointments for pelvic floor muscle training with biofeedback with a pelvic floor physical therapist. The primary outcome was long-term (at least 4 years) symptomatic improvement in predominant diagnosis after pelvic floor muscle training with biofeedback. This study was approved by the Institutional Review Board at University of Tennessee College of Health Science (formerly University of Tennessee- Memphis) and at University of Louisville and was conducted in compliance with the ethical standards of the responsible institution on human subjects as well as with the Helsinki Declaration, after obtaining informed consent from the study participants.

Subjects were contacted at approximately 4 years after their initial visit (range 4 - 5 years) by telephone or letter. They were asked to describe if their symptoms were better (classified as improved) or either the same or worse (classified as not improved) (Supplement 1, www.gastrores.org). Subjects were then stratified by "improved" or "not-improved" and review of clinical charts was performed for patient characteristics as well as EMG values.

\section{Statistical analysis}

We tabulated descriptive statistics, reporting baseline demographics and clinical characteristics with means and standard deviation (SD), or medians and interquartile range (IQR) as appropriate. Categorical data are presented as number with proportions. Continuous data were compared using the independent samples $t$-test, and categorical data were compared using Chi-square test (Fisher exact tests if $\mathrm{n}<5$ for any category). Area under the curve (AUC) and its absolute change (AUC after - AUC before) as area of improvement (AOI) were analyzed and compared by paired $t$-tests and reported as mean and SD. All tests were two sided and $\mathrm{P}$ values $<0.05$ were considered statistically significant. All statistical analyses were done using SPSS (IBM SPSS Statistics 25).

\section{Results}

During the study period, 41 subjects were contacted. Of these, $35(85.4 \%)$ were women and six $(14.6 \%)$ were men. The mean age was $48.95 \pm 15.46$ (range 22 - 77 years). The primary indication for biofeedback was constipation in 27/41 (65.9\%), 9/41 (22\%) reported FI and 5/41 (12.1\%) reported other (3/41 reported diarrhea and 2/41 reported anal pain). Long-term improvement was noted in $61 \%(25 / 41)$ while $39 \%(16 / 41)$ reported feeling the same or no improvement. Within the patients who reported constipation as their primary complaint, 55.6\% reported maintaining their improvement long term as compared to $66.7 \%$ of FI and $80 \%$ of the other patients (Table 1 ).

There was a borderline difference in the baseline resting EMG values between the groups $(3.11 \pm 1.85 \mu \mathrm{V}$, improved vs. $7.41 \pm 11.01 \mu \mathrm{V}$, not improved, $\mathrm{P}=0.06)$ but no significant difference in baseline contraction EMG $(7.08 \pm 5.03 \mu \mathrm{V}$, improved, and $7.79 \pm 10.47 \mu \mathrm{V}$, not improved, $\mathrm{P}=0.77)$. There was also no significant difference in post-exercise resting EMG $(3.13 \pm 3.21 \mu \mathrm{V}$, improved, and $4.28 \pm 3.63 \mu \mathrm{V}$, not improved, $\mathrm{P}=0.33)$ or contraction EMG $(6.39 \pm 6.41 \mu \mathrm{V}$ improved, and $6.61 \pm 6.38 \mu \mathrm{V}$, not improved, $\mathrm{P}=0.92$ ) (Fig. 1).

\section{Discussion}

Although biofeedback for the treatment of anorectal disorders has been in use since the 1970s, data about the long-term efficacy are still inconsistent and provide mixed evidence $[1,3]$. Traditional data has recommended the use of biofeedback in patients with dyssynergic constipation although some shortterm efficacy has been found in patients with slow-transit constipation [4]. Our patient population consisted of a mix of idiopathic, dyssynergic and slow-transit patients since the only exclusion criteria was anatomic abnormalities. Despite this, we noted over $55 \%$ improvement in the long term consistent with other studies, suggesting that the use of biofeedback may be expanded to other populations beyond dyssynergic constipation [4].

The long-term efficacy of biofeedback for FI is more contentious with poor quality studies [1]. Furthermore, the definition of long term is inconclusive with studies reporting 1 - 5 years as long-term data $[6,8]$. Mazor et al reported a 54\% improvement at 7 years as compared to the $75-80 \%$ improvement seen at 4 - 5 years suggesting a definite decrease in results 
Table 1. Baseline Characteristics

\begin{tabular}{llll}
\hline Characteristics & Improved, $\mathbf{n}=\mathbf{2 5}$ & Not improved, $\mathbf{n}=\mathbf{1 6}$ & P value \\
\hline $\begin{array}{l}\text { Age (years) } \\
\text { Gender }\end{array}$ & $49.08 \pm 15.7$ & $48.75 \pm 15.6$ & 0.95 \\
$\quad$ Male & $5 / 6(83 \%)$ & $1 / 6(17 \%)$ & 0.38 \\
$\quad$ Female & $20 / 35(57 \%)$ & $15 / 35(43 \%)$ & 0.71 \\
Indication & $15 / 27(56 \%)$ & & $12 / 27(44 \%)$ \\
$\quad$ Constipation & $6 / 9(67 \%)$ & $3 / 9(33 \%)$ & $1 / 5(20 \%)$ \\
$\quad$ Fecal incontinence & $4 / 5(80 \%)$ & & 0.06 \\
$\quad$ Other & & $7.41 \pm 11.01$ & 0.77 \\
Baseline EMG $(\mu \mathrm{V})$ & $3.11 \pm 1.85$ & $7.79 \pm 10.47$ & \\
$\quad$ Resting & $7.08 \pm 5.03$ & & \\
$\quad$ Contraction & &
\end{tabular}

EMG: electromyography.

over time $[6,7,14]$. Our study found a $67 \%$ improvement at 4 years after biofeedback confirming the long-term efficacy of biofeedback in the treatment of FI.

To improve allocation of resources, studies have looked at the variables which predict response to biofeedback. While age, stool consistency and depression scores all play some roles, the impact of baseline EMG has been debated [9-12]. Lacima et al found that subjects who demonstrated clinical improvement had higher baseline resting and contraction pressures although these results were not significant [12]. In this study, we found a borderline significant difference with those who reported long-term efficacy demonstrating lower baseline resting pressures. This difference was no longer visible after biofeedback contractions. In our population, baseline contraction pressures were similar between the groups and there was no significant difference in post-exercise contraction values between the groups.

Our study has several limitations. Participants in this study underwent biofeedback in the 1990 - 2000 and were contacted between 2004 and 2005, thus limiting us to the technology and non-validated questionnaires available at that time. The retrospective nature of this study limited our ability to obtain other

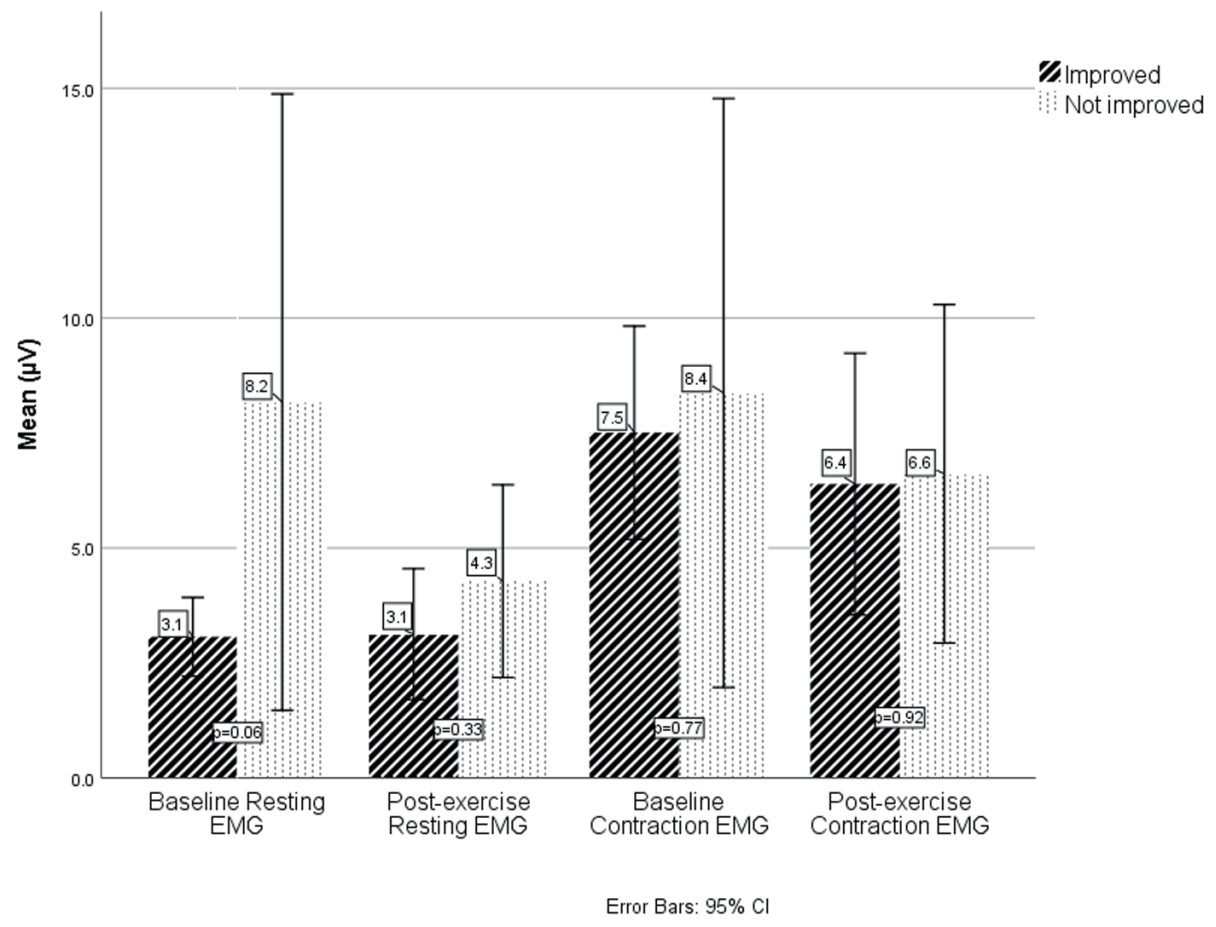

Figure 1. EMG values at baseline and after exercises in improved and not-improved respondents. EMG values are measured in microVolts $(\mu \mathrm{V})$. EMG: electromyography. 
pertinent characteristics and is subject to information and data collection biases from patients or providers. Additionally, records were not available for all the patients limiting sample size.

The strengths of our study lie in the standardization of biofeedback offered to all our patients especially since biofeedback was performed by the same physical therapist. The long follow-up also allowed us to assess efficacy in the long term and added to existing literature about long-term results in patients with anorectal disorders not limited to isolated constipation or FI.

In conclusion, our study found long-term efficacy in the use of biofeedback for constipation (55\%) and 67\% in FI consistent with other studies. EMG was not useful in predicting successful outcomes, but we did find a borderline significant lower resting baseline in patients who reported improvement of symptoms at least 4 years after biofeedback therapy. While biofeedback continues to be an important modality in the treatment of anorectal disorders, larger studies are needed to assess the use of EMG to predict and improve response.

\section{Acknowledgments}

The authors would like to thank the staff of the GI Division and GI Lab at UT-Memphis/UTCHS including Linda West RN for help with setting up the clinic and especially Patsy Moore RN for help with much of the patient care. The authors would like to thank Catherine McBride at the University of Louisville for help with manuscript preparation.

\section{Financial Disclosure}

No funding was received for this study.

\section{Conflict of Interest}

The authors declare no conflict of interest.

\section{Informed Consent}

Informed consent was obtained from the study participants.

\section{Author Contributions}

AG contributed to data analysis and manuscript writing; DTGH and SF were involved in project development and manuscript editing; MP, AAJ and TLA contributed to project development, data collection, and manuscript editing.

\section{References}

1. Rao SS, Benninga MA, Bharucha AE, Chiarioni G, Di Lorenzo C, Whitehead WE. ANMS-ESNM position paper and consensus guidelines on biofeedback therapy for anorectal disorders. Neurogastroenterol Motil. 2015;27(5):594-609.

2. Whitehead WE, Borrud L, Goode PS, Meikle S, Mueller ER, Tuteja A, Weidner A, et al. Fecal incontinence in US adults: epidemiology and risk factors. Gastroenterology. 2009;137(2):512-517, e511-512.

3. Enck P, Van der Voort IR, Klosterhalfen S. Biofeedback therapy in fecal incontinence and constipation. Neurogastroenterol Motil. 2009;21(11):1133-1141.

4. Battaglia E, Serra AM, Buonafede G, Dughera L, Chistolini F, Morelli A, Emanuelli G, et al. Long-term study on the effects of visual biofeedback and muscle training as a therapeutic modality in pelvic floor dyssynergia and slowtransit constipation. Dis Colon Rectum. 2004;47(1):9095.

5. Heymen S, Scarlett Y, Jones K, Ringel Y, Drossman D, Whitehead WE. Randomized controlled trial shows biofeedback to be superior to pelvic floor exercises for fecal incontinence. Dis Colon Rectum. 2009;52(10):17301737.

6. Lacima G, Pera M, Amador A, Escaramis G, Pique JM. Long-term results of biofeedback treatment for faecal incontinence: a comparative study with untreated controls. Colorectal Dis. 2010;12(8):742-749.

7. Mazor Y, Ejova A, Andrews A, Jones M, Kellow J, Malcolm A. Long-term outcome of anorectal biofeedback for treatment of fecal incontinence. Neurogastroenterol Motil. 2018;30(8):e13389.

8. Ozturk R, Niazi S, Stessman M, Rao SS. Long-term outcome and objective changes of anorectal function after biofeedback therapy for faecal incontinence. Aliment Pharmacol Ther. 2004;20(6):667-674.

9. Fernandez-Fraga X, Azpiroz F, Aparici A, Casaus M, Malagelada JR. Predictors of response to biofeedback treatment in anal incontinence. Dis Colon Rectum. 2003;46(9):1218-1225.

10. Shim LS, Jones M, Prott GM, Morris LI, Kellow JE, Malcolm A. Predictors of outcome of anorectal biofeedback therapy in patients with constipation. Aliment Pharmacol Ther. 2011;33(11):1245-1251.

11. Yu T, Shen X, Li M, Wang M, Lin L. Efficacy and predictors for biofeedback therapeutic outcome in patients with dyssynergic defecation. Gastroenterol Res Pract. 2017;2017:1019652.

12. Lacima G, Pera M, Gonzalez-Argente X, Torrents A, Valls-Sole J, Espuna-Pons M. Is electromyography a predictive test of patient response to biofeedback in the treatment of fecal incontinence? Neurourol Urodyn. 2016;35(3):390-394.

13. Thomas C, Lefaucheur JP, Galula G, de Parades V, Bourguignon J, Atienza P. Respective value of pudendal nerve terminal motor latency and anal sphincter electromyography in neurogenic fecal incontinence. Neurophysiol Clin. 2002;32(1):85-90.

14. Ferrara A, De Jesus S, Gallagher JT, Williamson PR, Larach SW, Pappas D, Mills J, et al. Time-related decay of the benefits of biofeedback therapy. Tech Coloproctol. 2001;5(3):131-135. 